\title{
THE EFFECTS OF CYCLOPHOSPHAMIDE AND ITS UROPROTECTIVE AGENTS, MESNA AND HYPERBARIC OXYGEN, ON URINARY BLADDER MOTILITY IN GUINEA PIGS
}

\author{
V. SAĞMANLIGIL ${ }^{1 *}$, Ö. ETLIK ${ }^{2}$, İ. PişKİN ${ }^{1}$ and A. TOMUR ${ }^{2}$ \\ ${ }^{1}$ Department of Physiology, Veterinary Faculty, Ankara University, 06110 Dışkapı, \\ Ankara, Turkey; ${ }^{2}$ Department of Physiology, Gülhane Military Medical Academy, \\ 06018 Etlik, Ankara, Turkey
}

(Received February 9, 1999; accepted June 24, 1999)

\begin{abstract}
The aim of this research was to observe the effects of cyclophosphamide and its uroprotective agents, mesna and hyperbaric oxygen (HBO), on the motility of urinary bladder muscle in guinea pigs. In the experimental groups, mesna and cyclophosphamide were intraperitoneally injected at a dose of $21.5 \mathrm{mg} / \mathrm{kg}$ and $68.1 \mathrm{mg} / \mathrm{kg}$, respectively. For the combination of mesna and cyclophosphamide, one dose of mesna was injected $20 \mathrm{~min}$ before cyclophosphamide administration and three additional injections of mesna were repeated every three hours. A total of $8 \mathrm{HBO}$ exposures were performed at 2.8 ATA for 90 min twice daily for another experimental group. In the HBO and cyclophosphamide combined group 5 HBO exposures were given prophylactically before cyclophosphamide. The combination of mesna, HBO and cyclophosphamide was administered by the same procedure. The contractions obtained in response to acetylcholine $\left(\mathrm{ACh}, 10^{-4} \mathrm{M}\right)$ in the control group were reduced using cyclophosphamide and HBO individually, but not by mesna. However, the contractions belonging to the various combinations of these three agents were not different from those seen in the control group. On the other hand, the combinations of cyclophosphamide, mesna and HBO showed higher responses to ACh than the groups in which cyclophosphamide and HBO were used individually, while the responses elicited by the cyclophosphamide and HBO combination were greater than those seen in the group treated with HBO only.
\end{abstract}

Key words: Cyclophosphamide, mesna, HBO, motility, urinary bladder, guinea pigs

The urinary bladder is an end organ that plays an important role in the excretion of many toxic drugs such as cyclophosphamide, a chemotherapeutic agent extensively used in the treatment of a wide variety of cancer cases and as an immunosuppressive drug given before transplantation in humans (Forni et al.,

*E-mail: sagmanli@veterinary.ankara.edu.tr; Fax: (312) 3164472 
1964; Beyer-Boon et al., 1978). In veterinary medicine, it is also used against lymphoreticular neoplasms (MacEwen et al., 1981; Stanton and Legendre, 1986) and for chemical shearing (Schlink and Macfarlane, 1978).

Cyclophosphamide is administered in an inactive form and is oxidized to 4-hydroxycyclophosphamide in the liver. This compound equilibrates nonenzymatically with aldophosphamide which is transported to the target cells by the circulatory system. In these cell populations, aldophosphamide undergoes a nonenzymatic cleavage to acrolein and phosphoramide mustard (Stanton and Legendre, 1986). Acrolein is believed to be responsible for sterile haemorrhagic cystitis and bladder fibrosis (Laing et al., 1988; Peterson et al., 1992). The development of a bladder neoplasm is another side effect in patients who have previously been treated with cyclophosphamide for a non-urologic malignant process (Fairchild et al., 1979).

Histologically, oedema and hyperaemia are seen after administration of one dose of the drug, and these are followed by mucosal hyperplasia and bizarre papillary proliferation. Contracted and oedematous smooth muscle fibres are further effects of the drug (DeVries and Freiha, 1990). Previously, Bonikos and Koss (1974) also reported changes in the pinocytic vesicles, partial or total necrosis of individual muscle cells, and formation of myelin figures.

Mesna (2-mercaptoethane sodium sulphonate) and HBO (hyperbaric oxygen) are well known uroprotective agents of cyclophosphamide (Freedman et al., 1984; Hader et al., 1993). Mesna forms a nontoxic thioether with acrolein, and has an additional inhibitory effect on the spontaneous release of acrolein from hydroxylated cyclophosphamide in the urine (Brock et al., 1981; Freedman et al., 1984). HBO treatment in cyclophosphamide-induced haemorrhagic cystitis promotes tissue healing by increasing tissue oxygen levels 10- to 15-fold. Thus increased oxygen tension decreases oedema and promotes capillary angiogenesis (Hader et al., 1993). In guinea pigs, it has recently been found that using the combination of mesna and HBO to prevent histological damage caused by cyclophosphamide was more effective than using either of them singly (Etlik et al., 1997).

The purpose of this investigation was to observe the possible detrimental effects of cyclophosphamide on urinary bladder contraction and also to determine whether these effects could be prevented by mesna and HBO either alone or in a combined form.

\section{Materials and methods}

In this study, 47 adult guinea pigs weighing $250-350 \mathrm{~g}$ were used. The animals were given food and water ad libitum and divided into 7 groups by the simple random sampling method shown in Table 1. 
Table 1

Cyclophosphamide, mesna and hyperbaric oxygen schedule

\begin{tabular}{|c|c|c|c|c|c|c|c|c|c|}
\hline \multirow{2}{*}{ Group } & \multirow{2}{*}{$\mathrm{n}$} & \multicolumn{2}{|c|}{ Day 1} & \multicolumn{2}{|c|}{ Day 2} & \multicolumn{2}{|c|}{ Day 3} & \multicolumn{2}{|c|}{ Day 4} \\
\hline & & $\mathrm{AM}$ & PM & $\mathrm{AM}$ & PM & $\mathrm{AM}$ & PM & $\mathrm{AM}$ & PM \\
\hline 1. Control & 6 & - & - & - & - & $\mathrm{PI}+\mathrm{PII}$ & $3 \times \mathrm{PI}$ & - & - \\
\hline 2. Mesna & 6 & - & - & - & - & $\mathrm{M}+\mathrm{PII}$ & $3 \times \mathrm{M}$ & - & - \\
\hline 3. $\mathrm{HBO}$ & 6 & HBO-1 & HBO-2 & HBO-3 & HBO-4 & $\begin{array}{l}\text { HBO-5 } \\
\text { PI + PII }\end{array}$ & $\begin{array}{l}\text { HBO-6 } \\
3 \times \text { PI }\end{array}$ & HBO-7 & HBO- 8 \\
\hline 4. Суc & 8 & - & - & - & - & $\mathrm{PI}+\mathrm{Cyc}$ & $3 \times$ PI & - & - \\
\hline 5. Сyc/M & 7 & - & - & - & - & $\mathrm{M}+\mathrm{Cyc}$ & $3 \times \mathrm{M}$ & - & - \\
\hline 6. $\mathrm{HBO} / \mathrm{Cyc}$ & 7 & HBO-1 & HBO-2 & HBO-3 & HBO-4 & $\begin{array}{l}\text { HBO-5 } \\
\text { PI + Cyc }\end{array}$ & $\begin{array}{l}\text { HBO- } 6 \\
3 \times \text { PI }\end{array}$ & HBO-7 & HBO-8 \\
\hline 7. $\mathrm{HBO} / \mathrm{Cyc} / \mathrm{M}$ & 7 & HBO-1 & HBO-2 & HBO-3 & HBO-4 & $\begin{array}{l}\mathrm{HBO}-5 \\
\mathrm{M}+\mathrm{Cyc}\end{array}$ & $\begin{array}{l}\mathrm{HBO}-6 \\
3 \times \mathrm{M}\end{array}$ & HBO-7 & HBO- 8 \\
\hline
\end{tabular}

$\mathrm{PI}=$ Physiological saline as placebo-I instead of mesna; PII = Physiological saline as placebo-II instead of cyclophosphamide; $\mathrm{HBO}=$ Hyperbaric oxygen treatment; $\mathrm{M}=$ Mesna; Cyc $=$ Cyclophosphamide

\section{Cyclophosphamide administration}

The animals were given a solitary, intraperitoneal, non-lethal and urotoxic dose of $68.1 \mathrm{mg} / \mathrm{kg}$ cyclophosphamide (Phillips et al., 1961).

\section{Mesna administrations}

Mesna at a dose of $21.5 \mathrm{mg} / \mathrm{kg}$ was administered intraperitoneally $20 \mathrm{~min}$ before cyclophosphamide injection and repeated every $3 \mathrm{~h}$ for a total of 4 doses (Freedman et al., 1984).

\section{HBO exposures}

A steel hyperbaric oxygen chamber was initially flushed with $100 \%$ oxygen and the chamber pressure was increased to 2.8 ATA in 10 min and gradually decompressing in $5 \mathrm{~min}$ to normobaric air at the end of the sessions. A temperature of $22-26{ }^{\circ} \mathrm{C}$ and an air flow of $15 \mathrm{l} / \mathrm{min}$ was maintained in the medium for a period of 90 min. Groups 3, 6 and 7 were exposed to HBO twice a day with an 
interval of $6 \mathrm{~h}$ for a total of 8 sessions. Since it was reported that the timing of HBO treatment was critical to its protective effects and 5 prophylactic HBO exposures before acrolein administration provided an effective protection, intraperitoneal (i.p.) administrations were performed at the end of the $5^{\text {th }} \mathrm{HBO}$-session according to Table 1. The experimental procedure including 3 additional HBO exposures was then completed at the end of Day 4 (Hader et al., 1993).

On Day 5, the guinea pigs were sacrificed using a high i.p. injection of $50 \mathrm{mg} / \mathrm{kg}$ pentobarbital sodium, and care was taken to avoid inadvertent bladder puncture. The bladders were removed and cut into strips of $1.5 \mathrm{~cm}$ length. The strips were tied at both ends and placed into an organ bath of $37{ }^{\circ} \mathrm{C}$ containing $40 \mathrm{ml}$ of oxygenated $\left(95 \% \mathrm{O}_{2}\right.$ and $\left.5 \% \mathrm{CO}_{2}\right)$ Tyrode's solution and 11 distilled water. An initial tension of $3 \mathrm{~g}$ was placed on each tissue $(1 \mathrm{mV} / \mathrm{cm}=10 \mathrm{~g}$; $25 \mathrm{~mm} / \mathrm{min}$ ) which was allowed to equilibrate for $60 \mathrm{~min}$.

Acetylcholine (ACh) was used as the muscarinic cholinergic secretagogue. In order to determine the optimum dose of ACh on the bladder of guinea pigs, various concentrations of ACh $\left(10^{-7} \mathrm{M}, 3 \times 10^{-7} \mathrm{M}, 10^{-6} \mathrm{M}, 3 \times 10^{-6} \mathrm{M}, 10^{-5} \mathrm{M}\right.$, $\left.3 \times 10^{-5} \mathrm{M}, 10^{-4} \mathrm{M}, 3 \times 10^{-4} \mathrm{M}, 10^{-3} \mathrm{M}\right)$ were applied to tissues taken from the control group, and the non-cumulative concentration-response curve of ACh was obtained (Fig. 1). The tissues taken from all experimental groups were then exposed to the optimum dose of $\mathrm{ACh}$ and the mean values of contractions of each group were normalised as the percentage of the value of the control group $(100 \%)$.

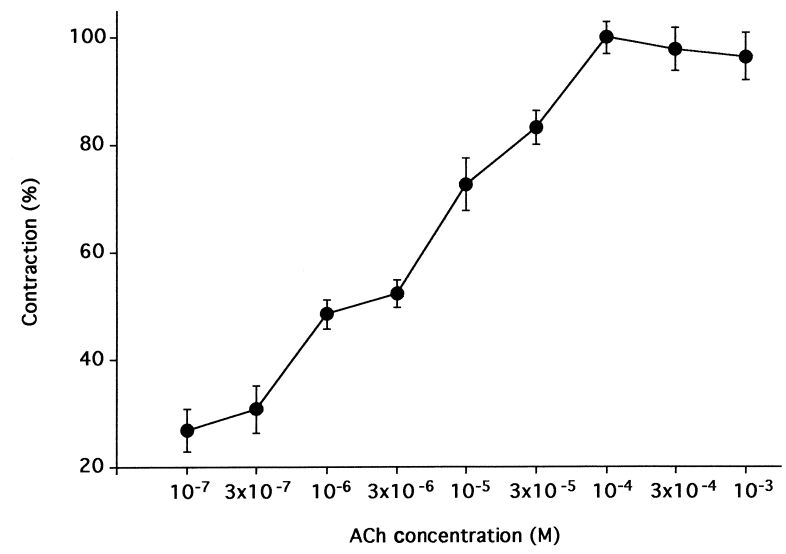

Fig. 1. Non-cumulative concentration-response curve for acetylcholine-induced contractions in the guinea pig bladder $(\mathrm{n}=6)$. Results are plotted as mean \pm SEM

\section{Statistics}

All results are shown as the mean \pm SEM. Statistical comparisons were accomplished using ANOVA and Duncan's test with 0.05 as the level of significance. 


\section{Results}

In an initial series of experiments, the effects of various concentrations of ACh on smooth muscle of urinary bladder of the control group (Group 1) were observed by drawing a non-cumulative concentration-response curve (Fig. 1). This curve showed that the highest response $(23 \mathrm{~mm})$ was seen at $10^{-4} \mathrm{M}$ and this was accepted as $100 \%$. The traces of the responses to various concentrations of $\mathrm{ACh}$ in the control group were also shown in Fig. 2 and they approximately represent the mean values.

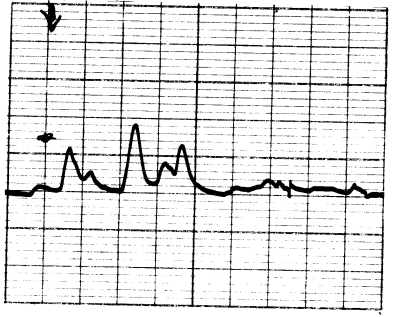

$10^{-7} \mathrm{M}$

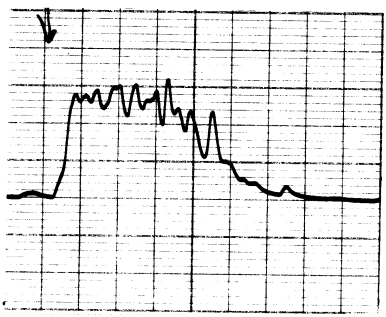

$3 \times 10^{-6} M$

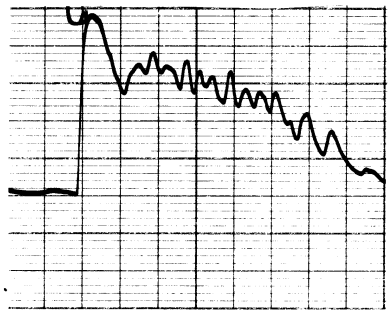

$10^{-4} \mathrm{M}$

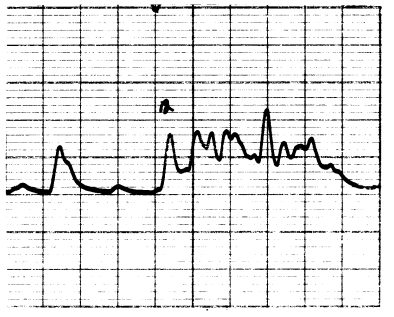

$3 \times 10^{-7} \mathrm{M}$

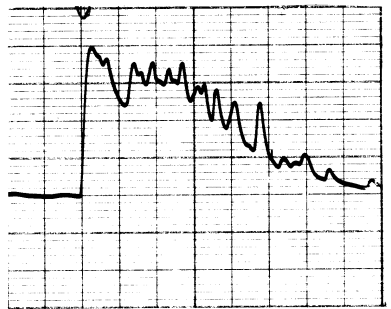

$10^{-5} \mathrm{M}$

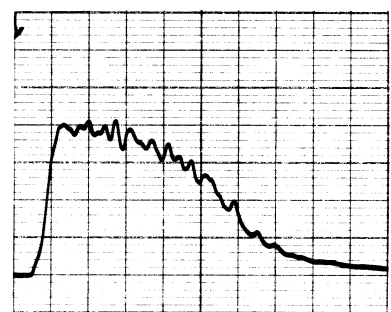

$3 \times 10^{-4} M$

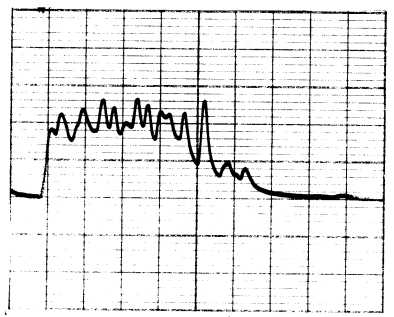

$10^{-6} \mathrm{M}$

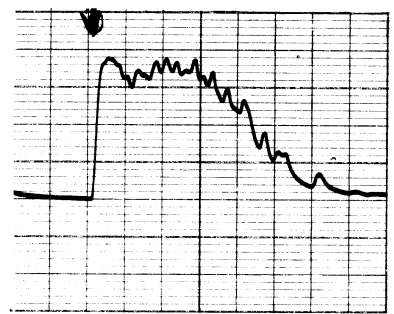

$3 \times 10^{-5} \mathrm{M}$

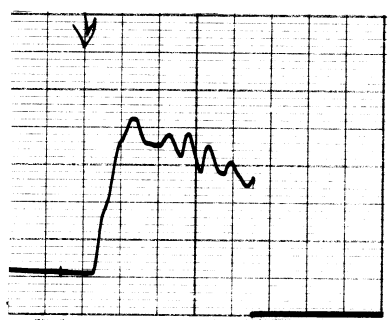

$10^{-3} \mathrm{M}$

Fig. 2. Responses of smooth muscle of urinary bladder to various concentrations of acetylcholine in the control group $(10 \mathrm{mV} / \mathrm{cm}=10 \mathrm{~g} ; 25 \mathrm{~mm} / \mathrm{min})$ 
In the subsequent series of experiments, the contraction responses of the urinary bladder to $10^{-4} \mathrm{M} \mathrm{ACh}$ (Fig. 3) were measured in the groups pretreated with mesna (Group 2), HBO (Group 3), cyclophosphamide (Group 4), cyclophosphamide and mesna (Group 5), cyclophosphamide and HBO (Group 6) and finally cyclophosphamide, mesna and HBO (Group 7). According to the 0.05 level of significance, tissue contraction at a dose of $10^{-4} \mathrm{M}$ ACh in Group 3 (HBO) was smaller than that in Group 1 (44\%), Group 2 (38\%), Group $5(42 \%)$, Group $6(36 \%)$ and Group $7(49 \%)$. In addition, the contraction obtained in Group 4 (cyclophosphamide) was also smaller than in Group 1 (23\%) and Group $7(30 \%)$. The traces obtained from these series of experiments were shown in Fig. 4 and they approximately represent the mean values.

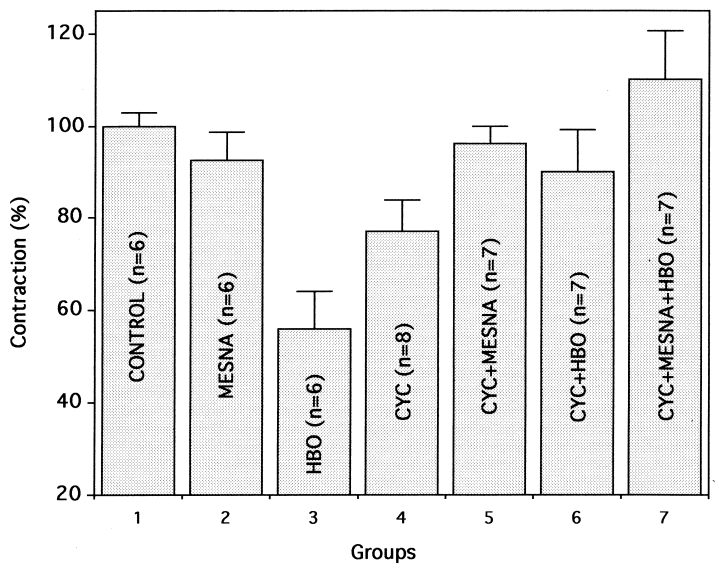

$\mathrm{p}<0.05: 1-3,1-4,2-3,3-5,3-6,3-7,4-7$

Fig. 3. Response to $10^{-4} \mathrm{M}$ acetylcholine of the urinary bladder of guinea pigs pretreated with physiological saline (control, Group 1), mesna (Group 2), hyperbaric oxygen (HBO, Group 3), cyclophosphamide (CYC, Group 4) and combinations of cyclophosphamide and mesna (CYC + MESNA, Group 5), cyclophosphamide and hyperbaric oxygen (CYC + HBO, Group 6) and finally cyclophosphamide, mesna and hyperbaric oxygen (CYC + MESNA + HBO, Group 7). Results are plotted as mean \pm SEM with the number of animals in brackets. The numbers below the histograms provide statistical comparisons

\section{Discussion}

Bonikos and Koss (1974) showed that cyclophosphamide caused splitting or duplication of the thickened membranes of dilated pinocytic vesicles, with formation of myelin figures and also necrosis of smooth muscle cells. These are possibly the reasons of muscular deficiency seen in the contractions of urinary bladder in guinea pigs pretreated with cyclophosphamide in response to $\mathrm{ACh}$. 
Our results are consistent with those of other investigations in that cyclophosphamide causes smooth muscle cell proliferation in blood vessels (Cragg et al., 1992; Modzelewski et al., 1994), an increase in the amount of connective tissue in the muscular tissue of the bladder (Lundbeck et al., 1993), smooth muscle necrosis in the stomach (Friedman et al., 1992), and depressed responses of the expansor secundariorum muscle to ACh in chicks (Lot and Onwukeme, 1991).

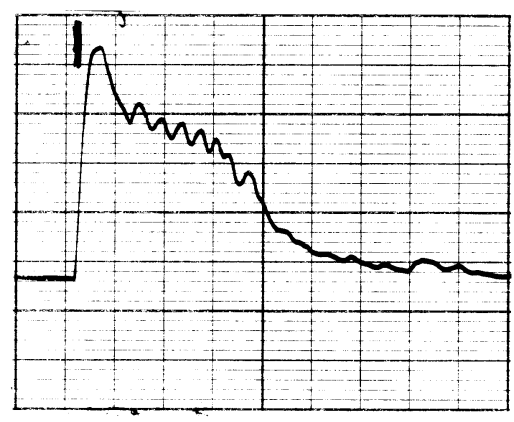

CONTROL

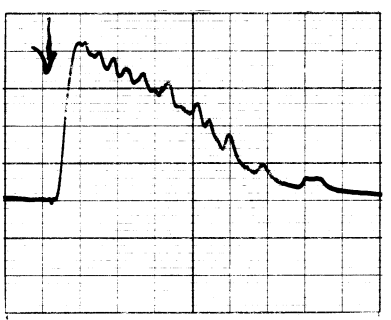

MESNA

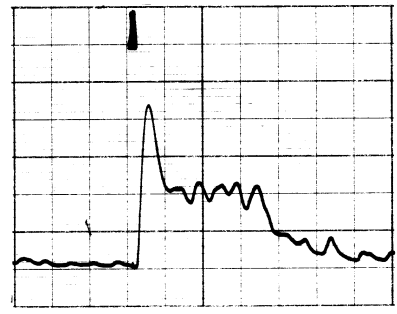

CYC+MESNA

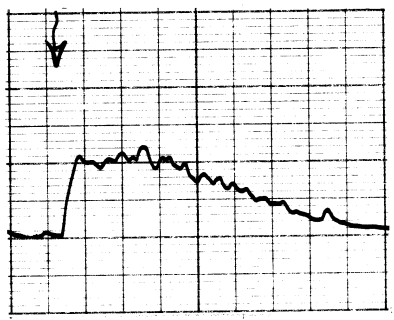

HBO

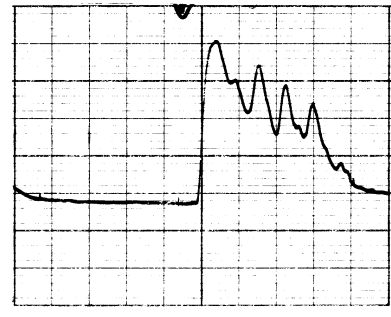

CYC+HBO

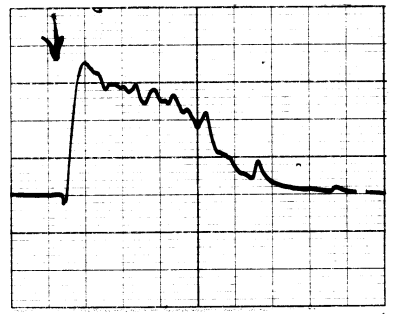

CYC

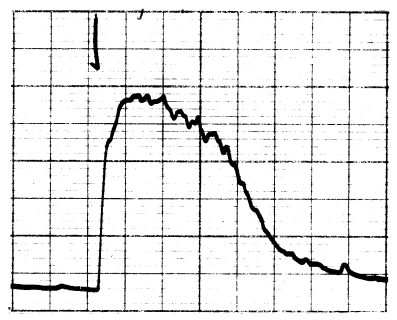

CYC+MESNA+HBO

Fig. 4. Responses of smooth muscle of urinary bladder to $10^{-4} \mathrm{M}$ acetylcholine in the control and experimental groups $(10 \mathrm{mV} / \mathrm{cm}=10 \mathrm{~g} ; 25 \mathrm{~mm} / \mathrm{min})$ 
A sulphhydryl group of mesna is believed to bind acrolein within the urinary collecting system and detoxify it (Brock and Pohl, 1983; Ormstad et al., 1982) thus preventing damage to the uroepithelium (Freedman et al., 1984). Mesna has also been used to block the myotoxic effects of cyclophosphamide metabolites in rat heart (Dorr and Lagel, 1994). ACh-induced contractions of muscle taken from the groups in which mesna was used alone and with cyclophosphamide were not significantly different from those of the control group. The possible protective mechanism of mesna in the uroepithelium can also be valid for the muscle of urinary bladder so that mesna prevented cyclophosphamide-caused damage in tissue by binding acrolein and preventing its entry into the muscular layers.

It is well known that $\mathrm{HBO}$ treatment promotes tissue healing in the uroepithelium in cyclophosphamide-induced oedema and hyperaemia (Hader et al., 1993). However, this treatment has negative effects on the smooth muscle of some organs such as the heart and the urinary bladder (Doubt and Evans, 1983; Hader et al., 1993). It was shown by Hader et al. (1993) that tissue hyperoxia increases the fibroblastic proliferation which is present in connective tissue and which is capable of forming collagen fibres. An important consideration about the direct effect of oxygen on myocardial cell function and negative inotropy during in the first 15 min was interpreted by Doubt and Evans (1983) as depressant effects of oxygen on a specific cellular event governing contractility. This effect can also be valid for the toxic effect of oxygen on distinct cellular processes in other tissues, and this was reviewed by Haugaard (1968). In his review, Haugaard pointed out that many metabolic alterations that occur in the tissue cells during hyperbaric oxygenation, such as an increase in the rate of oxidation of oxidizable substances, could be a simple mass action effect. A relaxation in rabbit pyloric sphincter muscle and also a rapid and reversible effect of oxygen on various smooth muscles at high pressure were interpreted as a reflection of a distinct, localized biochemical alteration in the cells. Bearing these facts in mind, it was thought that the possible biochemical changes of specific cells related to contraction and increase in connective tissue due to increased fibroblasts in HBO treatment, might have caused a deficiency in the contraction of the smooth muscle of the urinary bladder.

However, the results obtained using the cyclophosphamide and HBO combination cannot be explained easily even though they are in agreement with the findings of many studies (Hader et al., 1993; Etlik et al., 1997) which showed that the use of HBO prevented or treated the damaging effects of cyclophosphamide. The dissolved level of oxygen in plasma before cyclophosphamide injection would not be able to produce intracellular changes or proliferation of fibroblasts, but after injection it could reduce cyclophosphamideinduced damage. The effect may be described as a kind of neutralisation. 
A more interesting point is that adding mesna to this combination gave the highest response to $\mathrm{ACh}$, and this was not only significantly different from the value of the HBO group but also from that of cyclophosphamide. This is also parallel to a previous study (Etlik et al., 1997) that showed encouraging results on the uroepithelium when this trio was used. The protection provided by this combination was probably due to the protective effects of mesna not only on cyclophosphamide but also on HBO. It was explained by Haugaard (1968) that substances containing sulphhydryl groups can protect in vitro systems against oxygen toxicity or reactivate enzymes inhibited by oxygen. On the other hand, Haugaard also mentioned a progressive accumulation of the disulphide form of substance when a sulphhydryl compound is oxidized in an animal during hyperbaric oxygenation. The highest amplitude obtained in response to $\mathrm{ACh}$ in this combination could be due to a reverse potentiation between mesna and HBO.

In conclusion: cyclophosphamide and HBO reduced the contractile ability of smooth muscle of the urinary bladder when they were used separately. This was reversed by using HBO and mesna with cyclophosphamide in various combination forms. In all these forms, the results were indistinguishable from those of the control group but the last form produced the highest performance of muscle in response to $\mathrm{ACh}$.

\section{References}

Beyer-Boon, M. E., De Voogt, H. J. and Schaberg, A. (1978): The effects of cyclophosphamide treatment on the epithelium and stroma of the urinary bladder. Eur. J. Cancer 14, 1029-1035.

Bonikos, D. S. and Koss, L. G. (1974): Acute effects of cyclophosphamide on rat urinary bladder muscle. Arch. Pathol. 97, 242-245.

Brock, N. and Pohl, J. (1983): The development of mesna for regional detoxification. Cancer Treat. Rev. 10, 33-43.

Brock, N., Pohl, J. and Stekar, J. (1981): Studies on the urotoxicity of oxazaphosphorine cytostatics and its prevention. 2. Comparative study on the uroprotective efficacy of thiols and other sulfur compounds. Eur. J. Cancer Clin. Oncol. 17, 1155-1163.

Cragg, A. H., Stoll, L. L., Smith, T. P. and Berbaum, K. (1992): Effects of antineoplastic agents on smooth muscle cell proliferation in vitro: implications for prevention of restenosis after transluminal angioplasty. J. Vasc. Interv. Radiol. 3, 273-277.

DeVries, C. R. and Freiha, F. S. (1990): Hemorrhagic cystitis: A review. J. Urol. 143, 1-9.

Dorr, R. T. and Lagel, K. (1994): Effects of sulphhydryl compounds and glutathione depletion on rat heart myocyte toxicity induced by 4-hydroperoxycyclophosphamide and acrolein in vitro. Chem. Biol. Interact. 93, 117-128.

Doubt, T. J. and Evans, D. E. (1983): Effects of hyperbaric oxygen exposure at 31.3 ATA on spontaneously beating cat hearts. J. Appl. Physiol.: Respirat. Environ. Exercise Physiol. 55, 139-145.

Etlik, Ö., Tomur, A., Deveci, S., Pişkin, İ. and Pekcan, M. (1997): Comparison of the uroprotective efficacy of mesna and HBO treatments in cyclophosphamide-induced hemorrhagic cystitis. J. Urol. 158, 2296-2299. 
Fairchild, W. V., Spence, C. R., Solomon, H. D. and Gangai, M. P. (1979): The incidence of bladder cancer after cyclophosphamide therapy. J. Urol. 122, 163-164.

Forni, A. M., Koss, L. G. and Geller, W. (1964): Cytological study of the effect of cyclophosphamide on the epithelium of the urinary bladder in man. Cancer 17, 1348-1355.

Freedman, A., Ehrlich, R. M. and Ljung, B-M. (1984): Prevention of cyclophosphamide cystitis with 2-mercaptoethane sodium sulfonate: A histologic study. J. Urol. 132, 580-582.

Friedman, H. D., Kurec, A. S., Goldberg, J., Coyle, T. E. and Poiesz, B. J. (1992): Large granular lymphocytosis terminating in a polymorphous B-lymphocytic proliferation after low-dose cyclophosphamide therapy: a case report with necropsy findings. Hematol. Pathol. 6, 209-218.

Hader, J. E., Marzella, L., Myers, R. A. M., Jacobs, S. C. and Naslund, M. J. (1993): Hyperbaric oxygen treatment for experimental cyclophosphamide-induced hemorrhagic cystitis. J. Urol. 149, 1617-1621.

Haugaard, N. (1968): Cellular mechanisms of oxygen toxicity. Physiol. Rev. 48, 312-373.

Laing, E. J., Miller, C. W. and Cochrane, S. M. (1988): Treatment of cyclophosphamide-induced hemorrhagic cystitis in five dogs. JAVMA 193, 233-236.

Lot, T. Y. and Onwukeme, K. E. (1991): A comparison of the effects of repeated administration of cyclophosphamide, cytosine arabinoside or their combination on smooth and skeletal muscle. In Vivo 5, 33-37.

Lundbeck, F., Nielsen, K. and Stewart, F. (1993): Late changes in the normal mouse bladder after irradiation alone or in combination with cis-DDP or cyclophosphamide, assessed by stereological analysis. APMIS 101, 275-280.

MacEwen, E. G., Brown, N. O., Patnaik, A. K., Hayes, A. A. and Passe, S. (1981): Cyclic combination chemotherapy of canine lymphosarcoma. JAVMA 178, 1178-1181.

Modzelewski, J. R., Daeschner, C., Joshi, V. V., Mullick, F. G. and Ishak, K. G. (1994): Venoocclusive disease of the liver induced by low-dose cyclophosphamide. Mod. Pathol. 7, 967-972.

Ormstad, K., Orrenius, S., Lastbom, T., Uehara, N., Pohl, J., Stekar, J. and Brock, N. (1982): Pharmacokinetics and metabolism of sodium 2-mercaptoethanesulfonate in the rat. Cancer Res. 43, 333-338.

Peterson, J. L., Couto, C. G., Hammer, A. S. and Ayl, R. D. (1992): Acute sterile hemorrhagic cystitis after a single intravenous administration of cyclophosphamide in three dogs. JAVMA 201, 1572-1574.

Phillips, F. S., Sternberg, S. S., Cronin, A. P. and Vidal, P. M. (1961): Cyclophosphamide and urinary bladder toxicity. Cancer Res. 21, Suppl. 1, 1557.

Schlink, A. C. and Macfarlane, W. V. (1978): Chemical shearing in the field trials of repeated doses of cyclophosphamide on pregnancy, wool growth and CPA tolerance. Proc. Aust. Soc. Anim. Prod. 12, Suppl. 1, 272.

Stanton, M. E. and Legendre, A. M. (1986): Effects of cyclophosphamide in dogs and cats. JAVMA 188, 1319-1322. 
